\title{
Percutaneous cholangioscopy to remove endovascular coils that had migrated into the bile duct after right hepatic artery pseudoaneurysm embolization
}

Right hepatic arterial injury is a common vascular injury during laparoscopic cholecystectomy, occurring in approximately $25 \%$ of patients with biliary injuries [1]. We report the case of a 78-year-old man who, 1 month after undergoing a laparoscopic cholecystectomy, was referred for hemobilia and collapse caused by the rupture of a cystic artery pseudoaneurysm into the common bile duct (CBD). Angiography showed active bleeding that was treated by conventional coil embolization [2] (॰ Fig. 1).

The patient was re-referred with obstructive cholangitis 1 month later ( Fig. 2), but endoscopic retrograde cholangiopancreatography (ERCP) failed owing to a bile duct stricture that could not be passed. We then performed percutaneous transhepatic biliary drainage to gauge the stricture over the course of a year ( $\triangleright$ Fig.3a). We removed the drain after 1 year with correct sizing of the stricture, but cholangitis subsequently recurred, requiring further percutaneous drainage prior to performing percutaneous cholangioscopy (CHF type V choledochoscope; Olympus, Tokyo, Japan). During cholangioscopy, we identified coils that had migrated into the CBD and easily removed these by pushing them

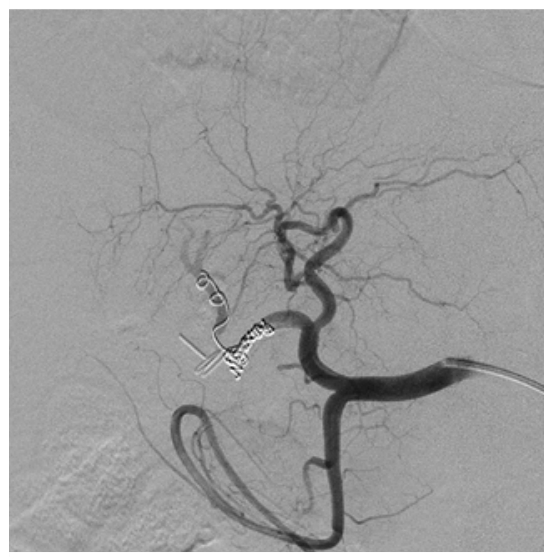

Fig. 1 Angiographic image in a 78-yearold man with rupture of a cystic artery pseudoaneurysm into the common bile duct, 1 month after undergoing a laparoscopic cholecystectomy, that was treated with coil embolization.

with a biopsy forceps into the duodenum ( $\triangleright$ Fig.3 b; $>$ Video 1). The patient was discharged with transhepatic drainage for an additional 3 months ( Fig. $3 \mathbf{c}$ ). We hope that the removal of the coils will improve CBD healing, although we fear the development of an ischemic biliary stenosis.

Few cases of coil migration into the CBD have been reported [3] and ERCP treat-

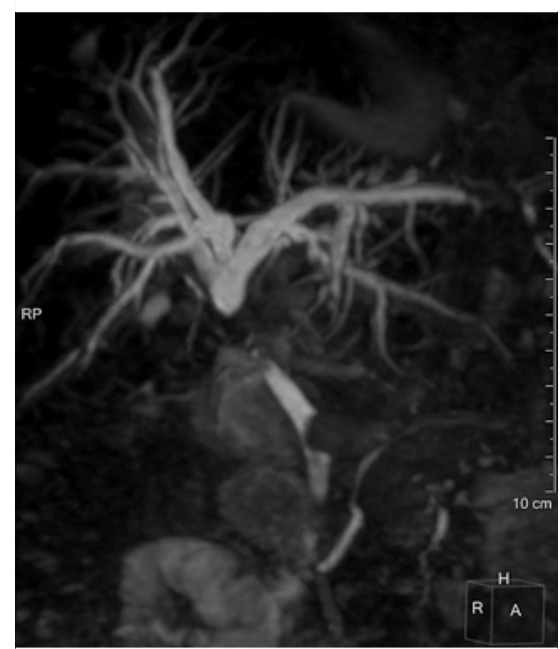

Fig. 2 Biliary magnetic resonance imaging performed after the patient developed obstructive cholangitis.

ment has been suggested [4], but the percutaneous approach is another option. In this video, we demonstrate the removal of migrated coils with a percutaneous endoscopic approach, thereby avoiding complex surgery.

Endoscopy_UCTN_Code_TTT_1AR_2AK
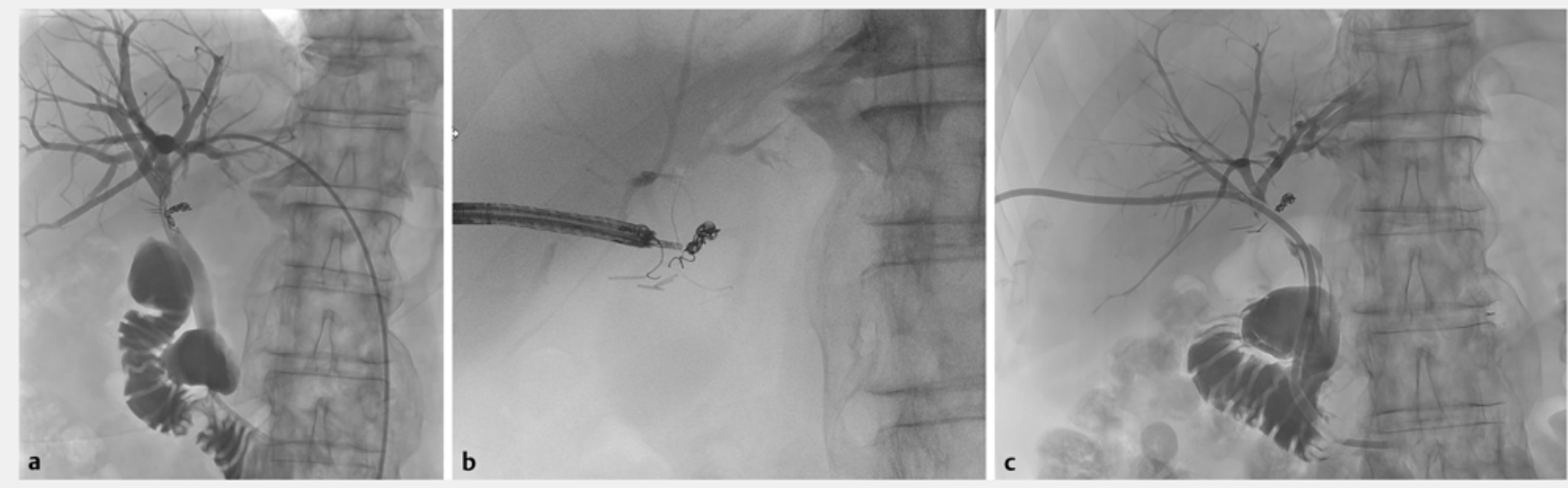

Fig. 3 Fluoroscopic images showing: a the initial cholangiographic appearance after percutaneous transhepatic biliary drainage; b coil removal during percutaneous cholangioscopy; c follow-up cholangiographic image. 


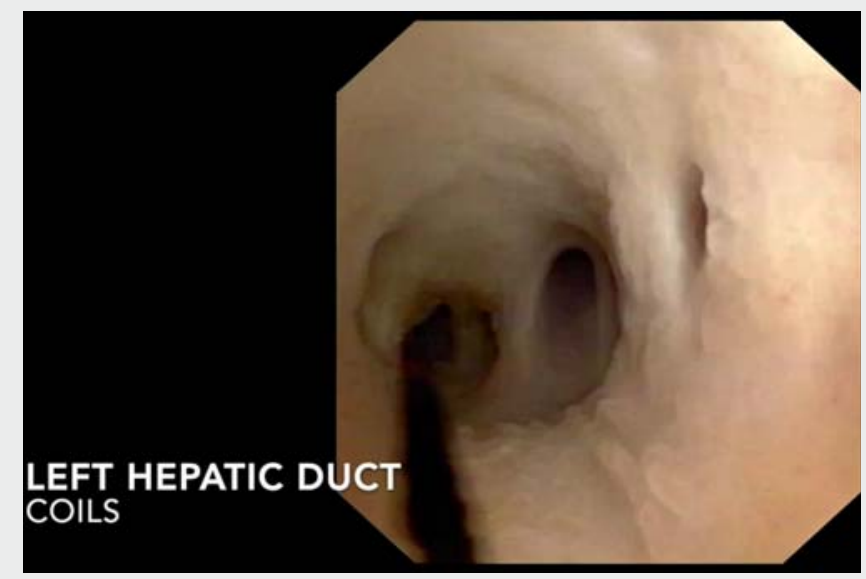

Video 1 Percutaneous cholangioscopy to remove endovascular coils that had migrated into the bile duct after right hepatic artery pseudoaneurysm embolization.

Competing interests

The authors declare that they have no conflict of interest.

The authors

Jérôme Rivory ${ }^{1}$, Badis Menassel ${ }^{2}$, Thomas Lambin', Florian Rostain ${ }^{1}$, Laurent Milot ${ }^{2}$, Thierry Ponchon ${ }^{1}$, Mathieu Pioche ${ }^{1,3}$

1 Department of Endoscopy and Gastroenterology, Pavillon L, Edouard Herriot Hospital, Lyon, France

2 Department of Radiology, Pavillon B, Edouard Herriot Hospital, Lyon, France

3 Inserm U1032 LabTau, Lyon, France

\section{Corresponding author}

\section{Jérôme Rivory, MD}

Endoscopy unit - Digestive Disease department, Pavillon L - Edouard Herriot Hospital, 69437 Lyon , France

jerome.rivory@chu-lyon.fr

\section{References}

[1] Strasberg SM, Helton WS. An analytical review of vasculobiliary injury in laparoscopic and open cholecystectomy. HPB 2011; 13 : $1-14$

[2] Tulsyan N, Kashyap VS, Greenberg RK et al. The endovascular management of visceral artery aneurysms and pseudoaneurysms. J Vasc Surg 2007; 45: 276-283
[3] Raashed S, Chandrasegaram MD, Alsaleh K et al. Vascular coil erosion into hepaticojejunostomy following hepatic arterial embolisation. BMC Surg 2015; 15: 51

[4] Kao WY, Chiou YY, Chen TS. Coil migration into the common bile duct after embolization of a hepatic artery pseudoaneurysm. Endoscopy 2011; 43: E364-E365

Bibliography

Endoscopy 2021; 53: E448-E449

DOI 10.1055/a-1322-1942

ISSN 0013-726X

published online 4.2.2021

(c) 2021. Thieme. All rights reserved. Georg Thieme Verlag KG, Rüdigerstraße 14, 70469 Stuttgart, Germany

\section{ENDOSCOPY E-VIDEOS}

https:/|eref.thieme.de/e-videos

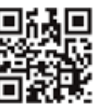

Endoscopy E-Videos is a free access online section, reporting on interesting cases and new

techniques in gastroenterological endoscopy. All papers include a high quality video and all contributions are freely accessible online.

This section has its own submission website at

https://mc.manuscriptcentral.com/e-videos 